\title{
Uma nova espécie de Gorytocephalus Nickol e Thatcher, 1971 (Acanthocephala: Neoechinorhynchidae) do acari bodó (Pices: Locariidae) da Amazônia, Brasil
}

\author{
Vernon E. Thatcher $\left({ }^{\star}\right)$
}

\section{Resumo}

Gorytocephalus elongorchis n. sp. (Acanthocephala: Neoechinorhynchidae) é descrico do intesti. no do acari bodó (Plecostomus carinatus Steindach. ner), um peixe de água doce da Amazônia obtido perto de Manaus, Amazonas, Brasil. A nova espécie distingue-se da espécie típica do gênero, o G. plecostomorum Nickol e Thatcher, 1971, por ser maior, pela presença de testículos alongados, lemniscos mais longos e uma tromba esférica.

\section{INTRODUÇÃo}

Nickol \& Thatcher (1971) estabeleceram o gênero Gorytocephalus para incluir sua nova espécie G. plecostomorum de um peixe siluriformídeo da República de Panamá. Eles também incluiram no gênero a espécie chamada Neoechinorhynchus spectabilis por Machado Filho (1959), procedente de Piraçununga, São Paulo, Brasil, depois de ter comparado material emprestado da Fundação Oswaldo Cruz do Rio de Janeiro. O gênero foi caracterizado principalmente pela presença de uma extensão longitudinal, dorsal, do corpo chamado pelos autores um "dorsal crest" (ou seja uma crista dorsal) e a presença de um aparelho especial, muscular, em volta do bolsa da tromba designado um "muscular sling".

Durante as necrópsias de peixes do rio Solimões (cercanias de Manaus) feitas no Instituto Nacional de Pesquisas da Amazônia, Manaus, Brasil, foram encontrados vários exemplares de acontocéfalos em Plecostomus carinatus Steindachner (Siluriformes: Loricariidae) que, evidentemente, representam mais uma nova espécie do mesmo gênero, a qual é descrita a seguir.

\section{MÉTODOS E MATERIAIS}

Os métodos empregados no presente estudo foram os mesmos indicados por Thatcher
(1978). As medições dadas são do holótipo (macho) e da alótipo (femea), com os limites inferior e superior dos parátipos dados entre parênteses.

O nome específico faz referência à forma mais alongada dos testículos, já que as outras duas espécies do gênero os têm arredondados.

\section{Gorytocephaius elongorchis $n$. sp. (Fig. 1-6)}

Hospedeiro: Plecostomus carinatus Steindachner. Habitat: Intestino

Procedência: Lago Janauacá, Manaus, Amazonas, Brasil.

Holótipo e Alótipo: Instituto Nacional de Pesquisas da Amazônia (INPA).

Parátipos: INPA e Museu de Zoolcgia da Unıvers1dade de São Paulo.

DIAGNOSE ESPECÍFICA - Com as características do gênero. Tronco cilíndrico, ligeiramente curvado ventralmente, diminuindo seu diâmetro em ambas as extremidades. Proeminente crista dorsal presente por todo o comprimento do tronco. ( $\mathrm{Na}$ fêmea a crista estende-se em volta do ponto do tronco, deixando o poro genital em uma posição ventral; no macho a crista termina um pouco anteriormente e o poro genital fica terminal). Fêmea maior que o macho. Tromba arredondada, pequena, com 18 ganchos distribuídos em 3 séries de 6 ganchos cada. Bainha da tromba com paredes simples e em volta pelo aparelho muscular ("muscular sling" de Nickol \& Thatcher, 1971). Gânglio central arredondado, situado na parte posterior da bainha da tromba. Lemniscos desiguais, com dois núcleos no longo e um no curto. Núcleos gigantes do tronco ramificados, localizados 5 no lado dorsal e 1 no lado ventral. Os dois núcleos gigantes an-

( ") - Instituto Nacional de Pesquisas da Amazônia, Manaus. 
teriores, no lado dorsal, ficam pertos um ao outro. Sistema lacunar com vias principais situadas dorsal e ventralmente.

Macho: Tronco medindo $16,0 \quad(12,0-16,0)$ de comprimento e 1,6 (1,2-1,6) de diâmetro máximo diminuindo até $0,43 \quad(0,27-0,43)$ nas extremidades. Crista dorsal medindo 0.29 $(0,07-0,29)$ de altura mínima e $0,90(0,18-0,90)$

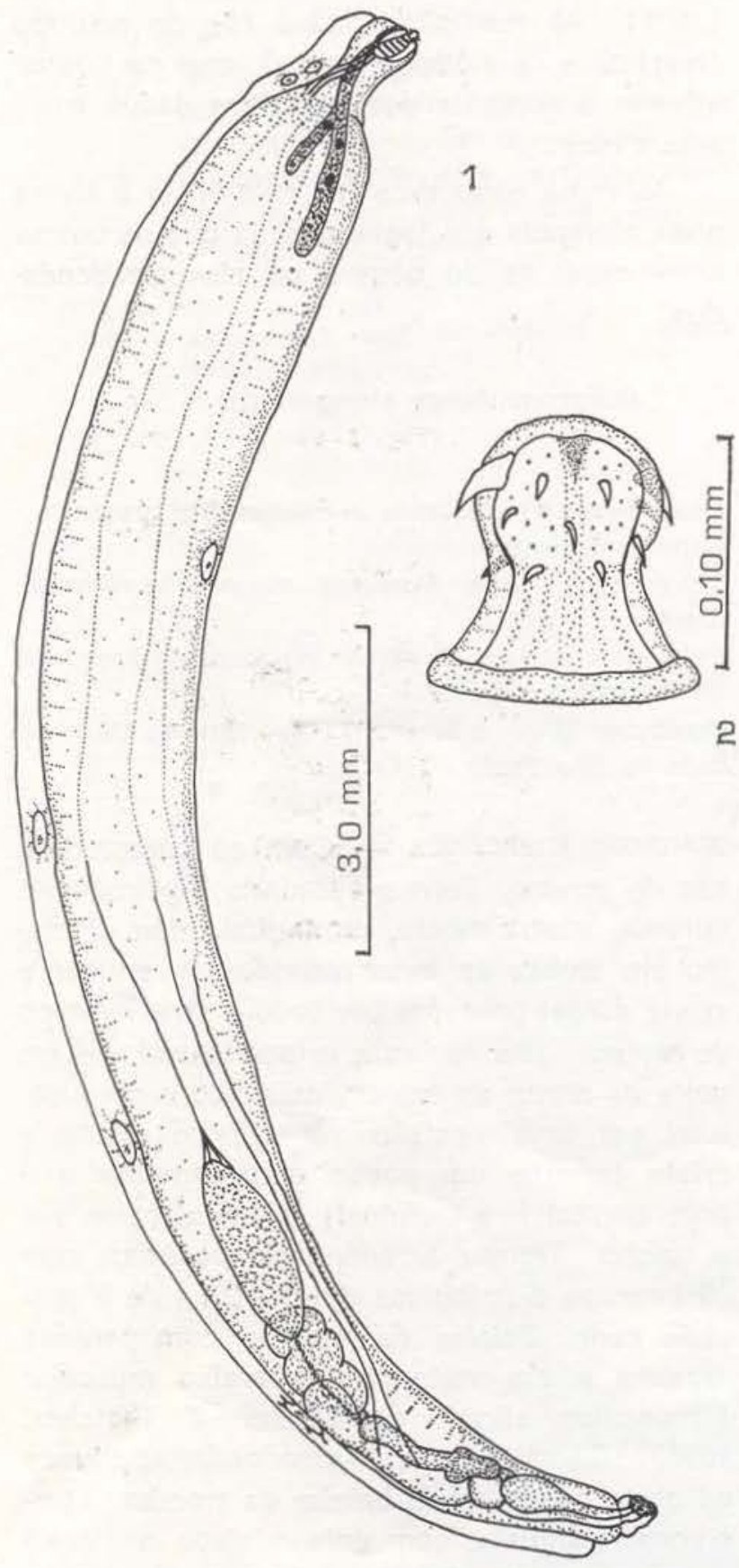

Gorytocephalus elongorchis n. sp : 1 - vista lateral do holótipo (macho); 2 - tromba estendida, mostrando ganchos. de altura máxima. Tromba medindo 72 (72-89) $\mu$ de comprimento e 72 (72-85) $\mu$ de diâmetro. Ganchos grandes da tromba medindo aproximadamente $36 \mu$ de comprimento e $24 \mu$ de largura. Ganchos pequenos das séries posteteriores da tromba medindo aproximadamente 7-8 $\mu$ de comprimento e $2-4 \mu$ de largura. Pescoço medindo 53 (36-53) $\mu$ de comprimento e 97 (85-97) $\mu$ de diâmetro. Bainha da tromba medindo $0,33 \quad(0,32-0,33)$ de comprimento $e$ $0,09(0,09-0,10)$ de largura. Gânglio central medindo 24-36 $\mu$ de diâmetro. Lemnisco longo medindo $2,5(2,5-2,7)$ de comprimento e 0,11 $(0,11-0,15)$ de largura. Lemnisco menor medindo $1,7 \quad(1,4-1,7)$ de comprimento e 0,07 $(0,07-0,08)$ de largura. Sistema reprodutor do macho ocupando $35 \%(23-35 \%)$ do comprimento do tronco. Testículos alongados, um atrás do outro, no terço posterior do tronco. Testículo anterior medindo $2,4 \quad(1,1-2,4)$ de comprimento e $0,60 \quad(0,32-0,60)$ de largura. Testículo posterior medindo $1,1(0,80-1,1)$ de comprimento e $0,60 \quad(0,28-0,60)$ de largura. Glândula de cimento cilíndrico, alongado, com uma constrição no fim do terço anterior. A glândula de cimento é sincicial com 8 núcleos arredondados e mede $1,7(0,46-1,7)$ de comprimento, $0,32(0,14-0,32)$ de diâmetro gera! e $0,22 \quad(0,12-0,22)$ de diâmetro na área da constrição. Reservatório de cimento esférico, medindo $0,47 \quad(0,23-0,47)$ de diâmetro. Bolsa de Saefftigen presente, medindo 0,85 $(0,59-0,85)$ de comprimento. Bolsa copuladora mede $0,45(0,16-0,45)$ de comprimento e 0,30 $(0,27-0,30)$ de largura.

Fêmea: Tronco medindo $17,2 \quad(12,3-22,0)$ de comprimento e $1,6(0,65-1,7)$ de diâmetro máximo diminuindo até $0.44 \quad(0,22-0,44)$ nas extremidades. Crista dorsal medindo 0,24 $(0,09-0,24)$ de altura mínima e $0,43(0,27-0,43)$ de altura máxima. Tromba medindo 72 (58-77) $\mu$ de comprimento e 86 (72-86) $\mu$ de diâmetro. Ganchos grandes aproximadamente 36 por 24 $\mu$ de tamanho. Ganchos pequenos mais ou menos 8 por $4 \mu$. Pescoço medindo 29 (36-31) $\mu$ de comprimento e $110(72-110) \mu$ de diâmetro. Bainha da tromba medindo $0,51 \quad(0,39-0,51)$ de comprimento e $0,11 \quad(0,09-0,12)$ de largura. Gânglio central medindo $31-53 \mu$ de diâmetro. Lemnisco maior medindo $3,4(1,5-3,4)$ de comprimento e $0,13(0,09-0,13)$ de largura. Lem- 


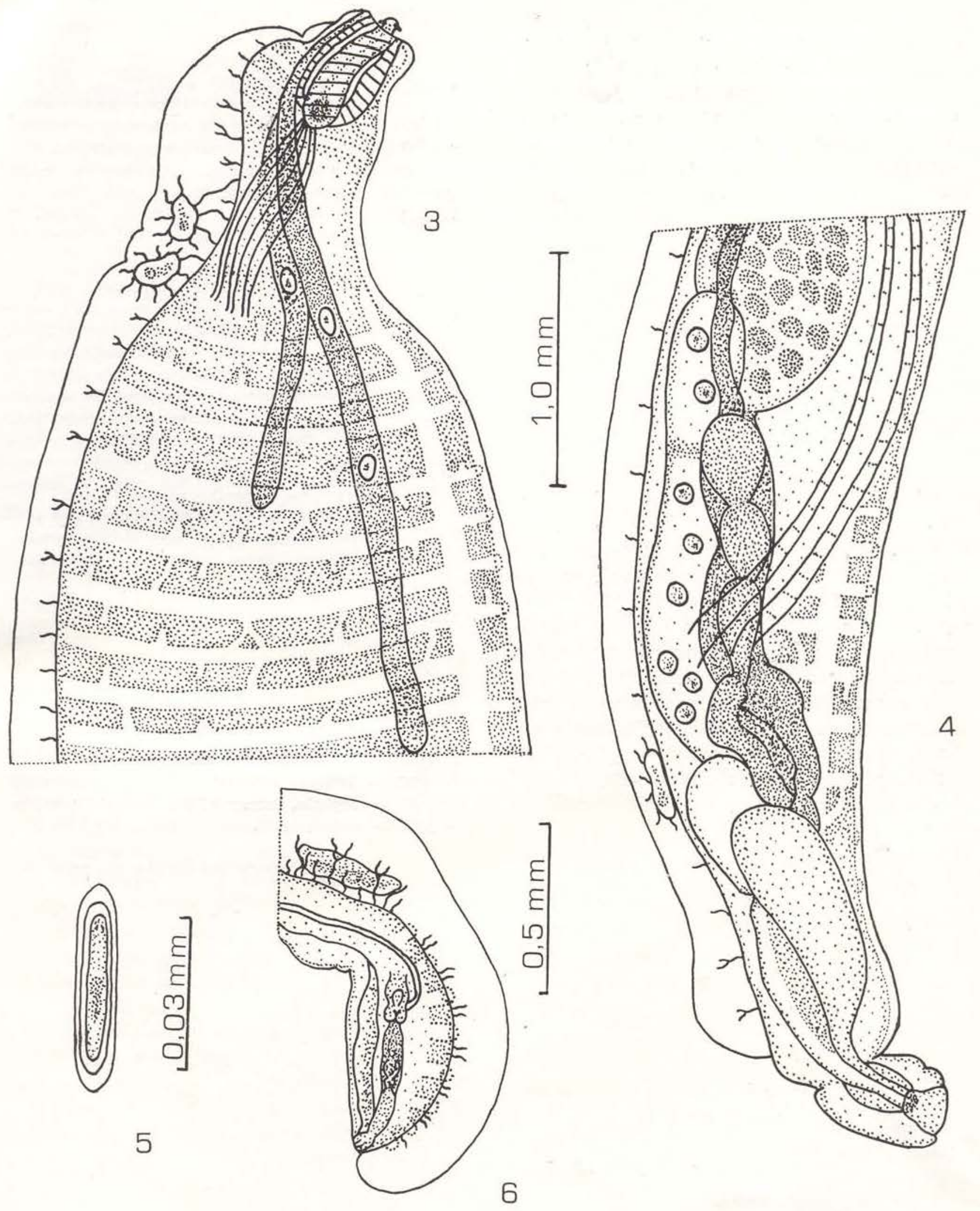

Gorytocephalus elongorchis n. sp.: 3 - extremidade anterior do holótipo; 4 - extremidade posterior do holótipo, mostrando complexo genital (mesma escala de 3); 5 - ovo; 6 - ertremidade posterior da fêmea, mostrando campainha uterina, vagina e poro genital. 
nisco menor medindo $1,7(0,86-1,7)$ de comprimento e $0,09(0,08-0,09)$ de largura. Sistema reprodutor ocupa $3,3 \%(2,1-3,3 \%)$ do comprimento do corpo medindo da margem anteroir da campaínha uterina até o poro genital Campaínha uterina mede $0,36(0,20-0,36)$ de comprimento e $0,05 \quad(0,05-0,09)$ de largura. Crista dorsal circundando o ponto posterior do tronco. Poro genital ventral. Ovos 13-14 x 43-46 $\mu$ em tamanho.

\section{Discussão}

Gorytocephalus elongorchis n. sp. aproxima-se mais da espécie típica do gênero, o G. plecostomorum Nickol e Thatcher, 1971. A nova espécie distingue-se dessa espécie em ter testículos alongados e não arredondados, uma crista dorsal mais baixa e um tamanho maior. Embora as trombas das duas espécies sejam aproximadamente do mesmo tamanho, suas formas são diferentes. A tromba da nova espécie é esférica enquanto que a de G. plecostomorum é cilíndrica. Nickol \& Thatcher (1971) consideraram a forma cilíndrica da tromba comø característica de importância genérica, mas aparentemente esta característica não é constante no gênero. Geograficamente as duas espécies estão separadas pela cordiIheira Andina e provavelmente estão adaptados a diferentes espécies de hospedeiros.

\section{SUMMARY}

Gorytocephalus elongorchis $\mathrm{n}$. $\mathrm{sp}$. (Acanthocephala: Neoechinorhynchidae) an intestinal parasite of a freshwater siluroid fish (Plecostomus carinatus Steindachner) taken in the Amazon river system near Manaus, Amazonas, Brazil, was described. The new species differed from the type species of the genus (G. plecostomorum Nickol and Thatcher, 1971) in being larger, having elongate instead of spherical testes, longer lemnisci and a spherical proboscis.

\section{BIBLIOGRAFIA}

Machado Filho, D.A.

1959 - Neoechinorhynchus spectabilis sp. n. (Neoechinorhynchidae, Acanthocephala). Rev. Brasil Biol., 19 : 191-194.

Nickol, B.B. \& THATCHER, V.E.

1971 - Two new acanthocephalans from neotropical fishes: Necechinorhynchus pro. chilodorum sp. n. and Gorytocephalus plecostomorum gen, et sp. n. J. Parasit., $57(3): 576-581$

THATCHER, V.E.

1978 - Quatro novas espécies de Haploporidae (Trematoda: Digenea) de peixes de água doce de Colômbia com uma revisão do gênero Saccocoelioides Szidat, 1954. Acta Amazonica, 8(3) : 477-484.

YAMAGUTI, $\mathrm{S}$.

1963 - Systema Helminthum, Vol. V., Acantho. cephala. Intersci. Pub. New York. 423 p.

(Aceito para publicação em $03 / 06 / 78$ ) 